beginning of this year Prof. Osborne Reynolds gave, in a remarkable paper, ${ }^{1}$ the results of experimental researches "On Thermal Transpiration of Gases through Porous Plates," and showed the existence of a class of very marked phenomena which had escaped the notice of other observers. More recently Dr. John H. Long has studied the diffusion of liquids, starting from the work of Graham, which must be regarded as the first and only general investigation of this subject we possess. Dr. Long's results will be briefly given in his own words, but it may be well to draw attention, as he does, to a few facts connected with the history of the subject. In two papers read before the Royal Society in 1850, Graham established that-

$\mathrm{x}$. The velocity of diffusion is different for each substance in solution.

2. The amounts of salt diffused in a given time from solutions of the same substance, but different concentrations, are very nearly proportional to the concentration.

3. The amount of salt diffused from a given solution increases with the temperature.

Fick subsequently showed that liquid diffusion may be compared to the conduction of heat, that is, the spread of salt particles through water is in many respects analogous to the spread of heat in a conducting body, and that formulæ, similar to those established by Fourier for the latter case, may be applied in the former.

Certain experimentalists then employed optical methods of observation in determining the rate of diffusion of salts in solution, but Stefan showed that the optical methods "are based on a false assumption, and that they can therefore give only false results." It will be sufficient to state, however, that after a careful review of the work of the several investigators, Dr. Long divides the researches into two classes:-

I. 'Those which are concerned with the physical side of the question, that is, with the determination of "the constant of diffusion" for a single substance. To this class belong the researches of Fick, Simmler, and Wild, Voit, Hoppe-Seyler, Johannisjanz, Weber, and Stefan.

2. Those which treat the subject from a chemical point of view, by comparing the rates of diffusion of many different substances. To this class belong the investigations of Graham, Beilstein, and Marignac. Dr. Long points out that " in regard to the first class it may be said that a very satisfactory end has been attained. The proof of Fick's law by Weber and Stefan, and the determination of the influence of temperature and concentration of solution by the former, leave little to be desired in connection with this part of the subject. The same cannot be said, however, of the other, the chemical side." The experiments of Beilstein are not sufficiently numerous to establish much with certainty, and those of Graham and Marignac, while agreeing well among themselves, do not establish the dependence of diffusion on the molecular weight or other physical property of the substance employed.

Facts such as these have led Dr. Long to undertake a lengthy series of experiments, in which he employed a method that renders it possible to determine the rate of diffusion from hour to hour, and to insure that the diffusion takes place into a medium whose concentration is always zero. His apparatus may be roughly described as consisting of a U-tube placed in a beaker, which contains the solution to be investigated. The ends of the tube are bent over the beaker, one end being connected with a funnel into which water slowly drops, displacing the solution in the U-tube, which flows out from the other end at about the rate of $40 \mathrm{cc}$. in an hour. The base of the U-tube is open, and is connected with a short vertical tube whose internal diameter is $15 \mathrm{~mm}$. This larger tube is open only at the bottom, and is arranged concentrically with the beaker.

I Proc. Roy. Soc., r879, p. 304.

A dissertation presented to the Faculty of Science of the University of Tübingen, $\mathbf{1}_{\mathbf{7}} 9$.
Diffusion thus takes place between the solution below the line of junction of the short tube with the U-tube and the water contained in the latter, the diffused particles being carried away and discharged; in other words, there is diffusion between a level of constant concentration and a level "of concentration zero." Space will only permit us to notice the general conclusions at which Dr. Long has arrived. He observes that no simple relation is recognisable between diffusion and other physical phenomena if we merely state the results in grammes of substance diffused. If, on the other hand, the results are stated as the numbers of molecules diffused, several interesting relations appear. For instance, it can be shown that the chlorides, bromides, and iodides of the alkaline metals form a series in which $\mathrm{NH}_{4}$ stands between $\mathrm{K}$ and $\mathrm{Na}$; and in this series the chloride, bromide, iodide, and cyanide of potassium have nearly the same rate. The chlorides of the dyad metals $\mathrm{Ba}, \mathrm{Sr}, \mathrm{Cr}$, and $\mathrm{Mg}$ are also seen to form a series as to their rates of diffusion. It can further be shown, by comparing Kohlrausch's results on the electrical conducting power of liquids with the diffusion rates, that those salts which in solution offer the least resistance to the passage of the galvanic current are the ones which diffuse most rapidly. In most cases it appears that the salts having the greatest molecular volume diffuse the best, and those salts which absorb the greatest amount of heat on passing into solution are also the ones which diffuse most rapidly.

Dr. Long shows that Graham's view that no relation exists between the molecular weight and the rate of diffusion requires modification, for the alkaline chlorides, bromides, and iodides stand in the same order as regards molecular volume, rate of diffusion, conducting power, and latent heat of solution.

In conclusion Dr. Long indicates the direction in which he proposes to continue the research, which, we may add, bears evidence of being the work of an able physicist, from whom many valuable researches may be expected. W. CHANDLER ROBERTS

\section{THE PARKES MUSEUM OF HYGIENE}

THERE is one all important matter with which neither the great Institution in Bloomsbury nor that at South Kensington has virtually any concern; this important matter is Hygiene, the knowledge and application of the laws of life, which in so far as they are perfect banish disease from the human race. The Parkes Museum of Hygiene has been formed to promote this department of the numerous applications of science.

In the spring of 1876 the movement for the formation of the Parkes Museum commenced. It was the outcome of a very general desire to perpetuate in some useful way the memory of the late Dr. Parkes, whose life had been so unselfishly spent in promoting the welfare and happiness of his fellows by extending the knowledge of the laws of health, and whose untiring energy and keen intellect did such good service in clearing away the ignorance and superstition which accepted disease as the inevitable accompaniment of human life in this world. The movement rapidly developed into shape, and finally the Parkes Museum of Hygiene was opened to the public in June last, with a fairly representative collection of mechanical appliances, models, plans, and books, designed to promote health, of which a descriptive and illustrated catalogue was published. Since then so many valuable additions have been made to the museum that an enlarged and improved catalogue has been issued. The affairs of the museum are administered by an executive committee of which Sir William Jenner is chairman, and at present the cost of maintaining the museum has to be met wholly by voluntary contributions. The collection of appliances, models, \&c., is temporarily located in the largest room of the south wing of University College, which, together 
with a second room for the Library, has been generously placed at the disposal of the executive committee, by the council of the College, until such time as a separate building can be provided for the museum. The articles exhibited are arranged in six classes, and a brief description of these will serve to indicate sufficiently that the museum is likely to be of great service to those engaged in studying the sanitary construction of houses and other branches of hygiene. It should be stated that the classification is only a temporary one.

In Class I. (Engineering) will be found plans, sections, and models of systems of drainage for cities, towns, and villages, including the whole of the contract drawings used in connection with the construction of the present system of drainage in the metropolis. Maps, \&c., illustrating the physical geography of this and other countries, plans of existing and proposed means of water supply for towns, sections of geological formations, and views of the position and surroundings of places noted as health resorts, apparatus in connection with water-supply, and the sinking of wells, are also included in this class.

Class II. (Architecture) consists of general designs for dwellings, hospitals, and other buildings, together with examples of the details of construction. This is by far the largest and most complete section of the museum; already it includes hundreds of models, or specimens of mechanical appliances, and modes of building construction-illustrating in detail the several parts of a well-built house, from the foundation to the roof-bricks, concrete, and other material for walls; artificial stone as a fireproof substitute for timber, \&c., so commonly used for heads over door and window openings; also water-closets of every description; baths; stoneware, lead, and iron pipes; syphon and other traps; yard gullies, and contrivances for disconnecting the main sewers from the house pipes, may be seen and compared. Windows and doors so arranged as to give ventilation to the apartment in which they are fixed, stoves of various kinds, ventilating gas lamps, cowls for chimneys, and soil pipes, and other mechanical appliances designed to promote health in connection with architecture, make up this department.

In Class III. (Furnishing) are arranged specimens of school and household furniture presenting features of hygienic interest, including English and foreign oil lamps, specimens of wall papers, arsenical and non-arsenical; and here it may be interesting to state that the library of the museum has been decorated throughout with the new paint, in which zinc white is used as a substitute for white lead.

Class IV. (Clothing) is intended to include fabrics of various kinds used for clothing, with explanation of their properties and uses; but at present this class is only represented by some specimens of army clothing, and a few articles of dress coloured with arsenical pigments.

Class V. (Food) has been largely contributed by the authorities at South Kensington and Kew. It includes a number of large diagrams illustrating the component parts of food and the adulteration of articles of food in common use; samples of gluten bread and other foods for invalids; preserved fruits, seeds, \&c.; different kinds of filters, and samples of water.

Class VI. (Preservation and Relief) is composed of all that relates to the hospital, the prevention of accidents or diseases peculiar to certain trades or occupations; disease charts, means for safety and rescue in case of fire, or accidents at sea ; stoves for disinfecting purposes, Turkish bath apparatus, \&c.

A library is being formed of books relating to hygiene. Exclusive of pamphlets, about 350 volumes are now deposited in the museum for reference, and in addition to these the reading-room is supplied with periodical publications and reports.

It will thus be seen that the Parkes Museum is fairly established. Owing to the limited means at the disposal of the Committee the museum is only opened to the public free on Tuesdays, Thursdays, and Saturdays, from Io to $2 o^{\prime}$ clock. This is perhaps a convenient time for architects, doctors, and other professional men, but it would be more completely supplying a public want if so beneficial an institution were opened during the evening, or at some such time when artizans and those actually engaged in building construction and sanitary work, might best avail themselves of the opportunities for gaining that enlightenment and knowledge which frequent and studious inspections of the contents of this museum of Hygiene would naturally afford them.

\section{NOTES}

THE building of the U.S. National Musetm is approaching completion at Washington. It stands in the close neighbourhood of the Smithsonian Institution, but is of so different a style of architecture that it will not seem to dwarf the older structure by comparison. The area required for the museum, Science News informs us, is 327 feet to a side; in all, about 100,000 square feet, which is a somewhat greater space than the "Government Building " covered at the Centennial Exhibition; but is intended to be capable of holding and satisfactorily showing at least twice as many objects. The building is a square, with ornamental towers at the corners. It rises by a succession of clerestories to a centre surmounted by a dome. The height of the roof at the outer edge is 27 feet; the central room covered by the dome is 90 feet ligh. Exclusive of the towers, there are seventeen rooms in the interior, and of these apartments five are 65 feet square, four are 65 by 52 , four are 91 by 52 , and four are ror by 65 ; the last mentioned being 45 feet high, and the rest of lesser heights except the one under the dome. The corner towers contain about 160 rooms, of which sixteen are 30 feet square, sixteen are 30 by 20 , and the remainder are about 13 feet square, but arranged in suites of twos and fours. The larger of the tower-rooms will probably be kept for distinct collections, open to the specialist but not to the public. In the general exhibition rooms, there will be 5,000 feet of dead wall against which cases can be placed, and these if set end to end would extend over 8,000 feet. The total length of shelving in these cases will be 28,000 feet; the area, 74,000 square feet; a visitor who examines all the cases will traverse a circuit of nearly three miles. The museum will contain all that the Government displayed at Philadelphia; all the exhibits of foreign cuuntries which were presented to the United States at the close of the Centennial show; the accumulations of the national surveys; the collections which are now overrunning the Smithsonian and the Patent Office, and a very extensive and complete exhibit of our fishing industries. Not a particle of wood will be used in constructing the building; hence it will be fireproof. It is to be warmed by steam in winter, and perhaps will be cooled in suimmer, so as to give a uniform temperature throughout the year.

THE death is amounced of Dr. Eduard Fenzl, of Vienna, Professor of Botany and director of the Imperial Botanical Cabinet. Dr. Fenzl was a member of the Vienna Academy of Sciences and vice-president of the Vienna Horticultural Society. He died on September 29 last at the age of seventy-two years.

AT Baden-Baden the German geologists held their meeting after that of the German Association was over, viz., on September 26 and 27. Prof. Knop, of Karlsruhe, presided. There were some sixty members present from all parts of Germany and Austria. Mineralogical, geological, and palæontological papers were read by Professors Beyrich, Knop, Beneke, Häusler, Baumhauer, Eck, von Mojsisovics, and Tschermak.

THE American Association have selected Boston for their meeting next year, a pressing invitation from San Francisco 